\title{
Meeting droplet size specifications for aerial herbicide application to control wilding conifers
}

\author{
Brian Richardson ${ }^{1,}{ }^{*}$, Carol A. Rolando ${ }^{1}$, Andrew J. Hewitt ${ }^{2}$ and Mark O. Kimberley ${ }^{1}$ \\ ${ }^{1}$ Scion (NZ Forest Research Institute Ltd), Private Bag 3020, Rotorua, New Zealand \\ ${ }^{2}$ The University of Queensland, Gatton, Queensland 4343, Australia \\ *Corresponding author: brian.richardson@scionresearch.com \\ (Original submission received 5 April 2020; accepted in revised form 10 August 2020)
}

\begin{abstract}
Large areas of New Zealand are being aerially sprayed with herbicides to manage 'wilding' conifer spread. The purpose of the study was to obtain and analyse droplet spectra produced by nozzles commonly used for wilding conifer spraying to determine whether or not operational recommendations for a target droplet size class $(\sim 350 \mu \mathrm{m})$ are being met. Droplet spectra were measured in a wind tunnel for 27 nozzle $\times$ 3 operating condition (nozzle angle, air speed and pressure) combinations tested for each of three spray mixes. AGDISP, an aerial spray application simulation model, was used to quantify the field performance implications of changes to droplet spectra parameters. Only one nozzle, the CP-09, $0.078,30^{\circ}$, met the target droplet size specification when used at $45^{\circ}$ but not at $0^{\circ}$. However, under these conditions, this nozzle produced a large driftable fraction. All but one of the other scenarios tested produced much larger droplet sizes. Operational spray mixes tended to slightly increase the potential for spray drift compared with the water control. The CP-09, $0.078,30^{\circ}$ nozzle used at $45^{\circ}$ met the operational droplet size specification but is more sensitive to changes to nozzle angle $\left(0^{\circ}\right.$ versus $\left.45^{\circ}\right)$ than the other nozzles tested. None of the three Accu-Flo ${ }^{\mathrm{TM}}$ nozzles tested met the target droplet size specification. However, the Accu-Flo ${ }^{\mathrm{TM}}$ nozzles produced very few fine droplets making them good choices for reducing spray drift potential.
\end{abstract}

Keywords herbicide, aerial spraying, AGDISP, nozzle, droplet spectrum, herbicide drift

\section{INTRODUCTION}

In New Zealand and many other parts of the world, introduced conifers have become major weed problems as they spread into areas beyond where they were planted (Ledgard 2001; Simberloff et al. 2010). Today, these 'wilding' conifers represent a significant environmental problem on over $2 \mathrm{M}$ ha of New Zealand's $27 \mathrm{M}$ ha land base (Froude 2011). Conifer species of concern include Pinus contorta (Dougl.), P. mugo (Turra), P. nigra (Arnold) and Pseudotsuga mensiesii (Mirb.) (Douglas-fir) (Ledgard 2001; Gous et al. 2010). The scale of the issue, the rapid expansion of the area being invaded, and the susceptibility of up to $20 \%$ of New Zealand's total land area (5.4 M ha) to further invasion by wilding conifers by 2035 (Froude 2011) led the New Zealand Government to implement a National Wilding Conifer Management Strategy (NWCMS) in 2014 (NWCMS 2014). The aim of the NWCMS is to prevent the spread of wilding conifers and to contain or eradicate established areas of wilding conifers by 2030.

One important element of the NWCMS is to undertake operations to control wilding conifers using mechanical (brush cutters, chainsaws), physical (hand-pulling, handsaws, loppers) and/or chemical methods. The selective and systemic herbicides triclopyr, triclopyr/picloram mixes and the non-selective systemic combination of glyphosate and metsulfuron provide effect control of most wilding conifers (Gous et al. 2010; Gous et al. 2014).

Aerial herbicide application is one of the few cost-effective treatment methods where there are widespread isolated trees or dense infestations of mature trees (Briden et al. 2014; Gous et al. 2014). Aerial application methods include: (a) broadcast (or boom) spraying, which is usually used to treat dense conifer stands (assessed as over 80\% ground cover with canopy) and results in good foliage coverage with spray (Gous et al. 2014);(b) aerial spot spraying of the foliage of individual trees; and (c) basal barking where a 'lance' or a 'wand' directs a jet of herbicide to the base of targeted trees (Gous et al. 2015). Herbicide treatment recommendations for broadcast aerial application have evolved over time. For example, the application of diquat followed by burning (Ray \& Davenhill 1991) is effective and was widely used for many years but it is rarely used today because of risks associated with fire. The current aerial boom spray recommendation for dense infestations of $P$. contorta, is based on a spray mix known locally as TDPA. This mix comprises $18 \mathrm{~kg}$ triclopyr (T), $5 \mathrm{~kg}$ dicamba (D), $2 \mathrm{~kg}$ picloram (P) and $0.28 \mathrm{~kg}$ aminopyralid (A), as well as adjuvants, applied aerially in $400 \mathrm{~L}$ water on a per hectare basis (Gous et al. 2014). The high water rate, applied as a double pass, is recommended to ensure the herbicide mix 
is effectively distributed over the crown of each conifer. Droplet size selection for this treatment is considered important with the need to balance the requirement of good foliar coverage while also minimising the risk of offsite drift and exposure to non-target species.

Droplet size spectra are often characterised using the volume median diameter $\left(\mathrm{D}_{\mathrm{v} 0.5}\right)$ where $\mathrm{D}_{\mathrm{v} 0 . \mathrm{x}}$ is the droplet diameter at which $0 . x$ fraction of the spray volume is contained in droplets with diameters less that the specified diameter. Relative Span (RS $=\mathrm{D}_{\mathrm{v} 0.9}-\mathrm{D}_{\mathrm{v} 0.1} / \mathrm{D}_{\mathrm{v} 0.5}$ ) is also used as an index of the spread of sizes around the $\mathrm{D}_{\mathrm{v} 0.5^{\circ}}$. The droplet spectra produced by different nozzles are generally classified from Extremely Fine to Ultra Coarse, based on the American Society of Agricultural and Biological Engineers (ASABE) standard (ASABE-Standards 2009; Fritz et al. 2012). Current droplet size recommendations for aerial boom spraying for wilding conifer control are to use nozzles that produce a $\mathrm{D}_{\mathrm{v} 0.5}$ of about $350 \mu \mathrm{m}$, equivalent to a 'Coarse' droplet spectrum classification, with $\mathrm{D}_{\mathrm{v} 0.5}$ in the range of $326-400 \mu \mathrm{m}$. Nozzles that produce 'Extremely or Ultra-coarse' droplets, with $\mathrm{D}_{\mathrm{v} 0.5}$ $>501 \mu \mathrm{m}$ are generally not recommended because coverage is reduced and ground deposition is increased for a given application volume rate (Richardson \& Thistle 2006). However, an exception is appropriate in situations where there are areas of high sensitivity to spray drift close to the target site. Operational guidelines recommend the selection of the nozzle with the smallest RS value (i.e. the lowest variation in droplet size around the selected $D_{v 0.5}$ ) where there is a choice of nozzles that meet the target classification. A useful indicator of the potential for spray drift is the spray volume contained in droplets with diameters of less than $150 \mu \mathrm{m}$, referred to as the driftable fraction (Fox et al. 1998).

Specific nozzle types and operating conditions to achieve target droplet spectra are not always specified in guidelines for wilding conifer control so there is uncertainty on how best to achieve operational guidelines. The droplet size classification in nozzle catalogues produced by manufacturers are typically based on spraying in static conditions using water but it is well known that many other factors, such as spraying speed, nozzle orientation on the boom and spray mixture physical properties, which can be modified using adjuvants, can have large effects on the droplet spectrum produced (Sundaram et al. 1985; Bouse 1994; Hoffmann et al. 2008; Fritz et al. 2009). Hence, the purpose of this study was to:

1. Determine the nozzle types and operating conditions currently used, or of future interest, for aerial spraying of herbicides to control dense infestations of wilding conifers.

2. Quantify the effect of selected nozzle types and operational variables, including aircraft flight speed, spray pressure and spray tank mix composition, on droplet size distribution.

3. Make inferences around the likely trade-offs between spray drift and foliar coverage for different nozzles and operating conditions.

4. Provide recommendations on nozzles that most closely meet the specifications in the aerial boom spraying guidelines.
AGDISP (Bilanin et al. 1989; Teske et al. 2003), a well validated (Bird et al. 2002; Hewitt et al. 2002; Teske et al. 2011), mechanistic spray model that simulates the landing position of droplets released in aerial and ground pesticide applications was used to quantify the operational/field performance implications of changes to droplet spectra parameters.

\section{MATERIALS AND METHODS}

\section{Nozzle selection}

Two contract managers overseeing many of New Zealand's aerial boom spraying operations for wilding conifer control in New Zealand, canvassed associated aerial applicators in 2017 to provide a list of nozzles that were either being used operationally or were of interest for future use. They also specified the typical operating conditions for these nozzles in terms of orientation on the boom, flying speed, and boom pressure. As a result, four classes of nozzle, 10 nozzle class/nozzle size combinations and 27 nozzle class/nozzle size and operating condition combinations were selected for droplet spectrum measurement (Table 1). The nozzle classes and types were:

- CP nozzles (Transland LLC. Wichita Falls, TX, USA), which have the benefit of easily being able to change flow rate and droplet size with a range of orifice sizes and spray deflection angles built into a single nozzle body. CP-09 nozzles were used with orifice sizes of 0.078 and 0.125 and a three-way deflector that could be set at $0^{\circ}$ (straight stream), $5^{\circ}$ or $30^{\circ}$.

- Accu-Flo ${ }^{\mathrm{TM}}$ nozzles (Bishop Equipment, Mfg., Inc., Hatfield PA, USA), which are effectively clusters of steel tubes with variable tube/orifice diameters that influence droplet size and flow rate. They are designed to create uniform droplet sizes with minimal production of fine driftable droplets. Three types were used:

$$
\begin{aligned}
& \text { ○.016, } 76 \text { tube, } \\
& \circ .020,64 \text { tube; and } \\
& \circ .028,64 \text { tube }
\end{aligned}
$$

- AIC or air induction nozzles (Teejet Technologies, Spraying Systems Co., Wheaton, IL, USA) that are designed to reduce the production of fine, driftable droplets. Two types were used, 10008 and 10010 that produce a $110^{\circ}$ flat fan spray pattern

- $\quad$ Disc and core nozzles (Teejet Technologies, Spraying Systems Co., Wheaton, IL, USA) that combine an orifice plate with a swirl plate that together influence both the flow rate and droplet size. One type was used, the D645 where D6 refers to orifice size 6, and 45 to the swirl plate category number 45 .

Operating conditions that were varied included nozzle angle (pointing straight back, $0^{\circ}$, or midway between 
Table 1 Nozzles and operating conditions selected for droplet size spectrum measurement in the University of Queensland wind tunnel.

\begin{tabular}{|c|c|c|c|c|c|}
\hline No. & Nozzle class & Nozzle type & Nozzle angle $\left({ }^{\circ}\right)^{\mathrm{a}}$ & Pressure (bar) & Airspeed (knots) \\
\hline 1 & $\mathrm{CP}$ & $09,0.125,30^{\circ}$ & 0 & 2 & 30 \\
\hline 2 & $\mathrm{CP}$ & $09,0.078,30^{\circ}$ & 0 & 2 & 30 \\
\hline 3 & $\mathrm{CP}$ & $09,0.125,5^{\circ}$ & 0 & 2 & 30 \\
\hline 4 & $\mathrm{CP}$ & $09,0.078,5^{\circ}$ & 0 & 2 & 30 \\
\hline 5 & $\mathrm{CP}$ & $09,0.125,30^{\circ}$ & 45 & 2 & 30 \\
\hline 6 & $\mathrm{CP}$ & $09,0.078,30^{\circ}$ & 45 & 2 & 30 \\
\hline 7 & $\mathrm{CP}$ & $09,0.125,5^{\circ}$ & 45 & 2 & 30 \\
\hline 8 & $\mathrm{CP}$ & $09,0.078,5^{\circ}$ & 45 & 2 & 30 \\
\hline 9 & Accu-Flo ${ }^{\mathrm{TM}}$ & .016 & 0 & 2 & 30 \\
\hline 10 & Accu-Flo ${ }^{\mathrm{TM}}$ & .020 & 0 & 2 & 30 \\
\hline 11 & Accu-Flo ${ }^{\mathrm{TM}}$ & .028 & 0 & 2 & 30 \\
\hline 12 & Accu-Flo ${ }^{\mathrm{TM}}$ & .020 & 0 & 2 & 35 \\
\hline 13 & Accu-Flo ${ }^{\mathrm{TM}}$ & .028 & 0 & 2 & 50 \\
\hline 14 & Accu-Flo ${ }^{\mathrm{TM}}$ & .016 & 45 & 2 & 30 \\
\hline 15 & Accu-Flo ${ }^{\mathrm{TM}}$ & .020 & 45 & 2 & 30 \\
\hline 16 & Accu-Flo ${ }^{\mathrm{TM}}$ & .028 & 45 & 2 & 30 \\
\hline 17 & Accu-Flo ${ }^{\mathrm{TM}}$ & .020 & 45 & 2 & 35 \\
\hline 18 & Accu-Flo ${ }^{\mathrm{TM}}$ & .028 & 45 & 2 & 50 \\
\hline 19 & AIC & 11008 & 0 & 2 & 35 \\
\hline 20 & AIC & 11008 & 0 & 3 & 35 \\
\hline 21 & AIC & 11008 & 45 & 2 & 35 \\
\hline 22 & AIC & 11008 & 45 & 3 & 35 \\
\hline 23 & AIC & 11010 & 0 & 2 & 35 \\
\hline 24 & AIC & 11010 & 0 & 3 & 35 \\
\hline 25 & AIC & 11010 & 45 & 2 & 35 \\
\hline 26 & AIC & 11010 & 45 & 3 & 35 \\
\hline 27 & Disc and Core & D6-45 & 0 & 4 & 50 \\
\hline
\end{tabular}

${ }^{a} 0^{\circ}$ represents a nozzle pointing straight back; $45^{\circ}$ represents a nozzle pointing mid-way between straight down and straight back.

straight down and straight back, $45^{\circ}$ ), system pressure, and airspeed. As a rule of thumb, droplet size is reduced when air shear at the nozzle tip increases through higher airspeeds and nozzles angled at $90^{\circ}$ relative to the air flow, or with higher pressures.

All droplet spectrum measurements were repeated using each of three spray mixes (Table 2): (i) water; (ii) metsulfuron; and (iii) TDPA. The metsulfuron mix is typically applied to control Douglas-fir wildings and the TDPA for pines such as P. contorta or P. mugo.

\section{Trial design and analysis}

\section{Main trial}

The design of the main trial was a 3-way balanced factorial with 3 replications and the following experimental factors (Tables 1 and 2): nozzle (9 combinations of nozzle class and size), nozzle angle ( 0 and 45 ), spray mixture (water,
TDPA, metsulfuron). The D6-45 nozzle class was excluded from this analysis because of its limited overall use with measurements taken only in the nozzle straight back orientation and at an airspeed of 50 knots. Of the other factors used in the analysis, pressure was held constant, (only data collected at 2 bars were used) and, apart from the D6-45 nozzle, speed was either 30 or 35 knots. These two similar speeds were used to align to operational specifications. For the data analysis, it was assumed that the difference in spectra from airspeeds between 30 and 35 knots would be small. This assumption was based on tests with the Accuflo 0.20 nozzle undertaken at both 30 and 35 knots, analysis of variance (ANOVA) confirmed there were no significant differences in the key parameters $D_{v 0.5}$ $(P=0.96)$ or driftable fraction (all values were 0.0 , so there was no variance). There was a significant effect of speed on $\mathrm{RS}(\mathrm{P}=0.004)$ but the change was relatively small (RS values of 0.48 and 0.54 for 30 and 35 knots respectively). 
Table 2 Contents of the three spray mixes used in droplet spectra measurements; all mixes applied at rates equivalent to $400 \mathrm{~L}^{2}$ water ha-1.

\begin{tabular}{|c|c|c|c|}
\hline Product name & Active ingredient & $\begin{array}{l}\text { Product in mix } \\
\text { amount ha- }\end{array}$ & NZ Manufacturer \\
\hline \multicolumn{4}{|l|}{ Spray mix 1: water only } \\
\hline- & - & - & - \\
\hline \multicolumn{4}{|c|}{ Spray mix 2: metsulfuron (Douglas-fir control) } \\
\hline Answer\# & $200 \mathrm{~g} \mathrm{~L}^{-1}$ metsulfuron methyl & $2.5 \mathrm{~kg}$ & Bayer Crop Science \\
\hline \multirow[t]{2}{*}{ Punch Penetrant } & Esterified seed oil & $10 \mathrm{~L}$ & ETEC Crop Solutions \\
\hline & & & (now UPL Ltd) \\
\hline \multirow[t]{3}{*}{ Slikka } & Heptamethyltrisiloxane & $2 \mathrm{~L}$ & ETEC Crop Solutions \\
\hline & & & (now UPL Ltd) \\
\hline & Ammonium sulphate & $4 \mathrm{~kg}$ & \\
\hline \multicolumn{4}{|c|}{ Spray mix 3: TDPA (mature pine control) } \\
\hline Grazon & $600 \mathrm{~g} \mathrm{~L}^{-1}$ triclopyr (BEE) & $20 \mathrm{~L}$ & $\begin{array}{l}\text { Dow AgroSciences (now Corteva } \\
\text { Agriscience) }\end{array}$ \\
\hline \multirow[t]{3}{*}{ Tordon Brushkiller XT } & $300 \mathrm{~g} \mathrm{~L}^{-1}$ triclopyr & $20 \mathrm{~L}$ & $\begin{array}{l}\text { Dow AgroSciences (now Corteva } \\
\text { Agriscience) }\end{array}$ \\
\hline & $100 \mathrm{~g} \mathrm{~L}^{-1}$ picloram & & \\
\hline & $8 \mathrm{~g} \mathrm{~L}^{-1}$ aminopyralid & & \\
\hline T-Max & $30 \mathrm{~g} \mathrm{~L}^{-1}$ aminopyralid & $4 \mathrm{~L}$ & $\begin{array}{l}\text { Dow AgroSciences (now Corteva } \\
\text { Agriscience) }\end{array}$ \\
\hline Dicamba 500 SL & $500 \mathrm{~g} \mathrm{~L}^{-1}$ dicamba & $10 \mathrm{~L}$ & Adria New Zealand, Ltd \\
\hline Punch Penetrant & $\begin{array}{l}\text { Modified vegetable oil and sur- } \\
\text { factant blend }\end{array}$ & $20 \mathrm{~L}$ & $\begin{array}{l}\text { ETEC Crop Solutions } \\
\text { (now UPL Ltd) }\end{array}$ \\
\hline \multirow[t]{2}{*}{ Li-700 } & & $0.5 \mathrm{~L}$ & $\begin{array}{l}\text { ETEC Crop Solutions } \\
\text { (now UPL Ltd) }\end{array}$ \\
\hline & Ammonium sulphate & $4 \mathrm{~kg}$ & \\
\hline
\end{tabular}

\#This product has since been discontinued by Bayer Crop Science. There are other many products that contain the active ingredient metsulfuron methyl such as AGPRO Meturon (AGPRO NZ, Ltd).

ANOVAs were used to test the significance of the main effects and interactions of experimental factors on the response variables, $\mathrm{D}_{\mathrm{v} 0.5}, \mathrm{RS}$, and driftable fraction. For all variables, the variance was not homogeneous, but varied among nozzle types. Therefore, heterogeneous ANOVAs were fitted with separate residual variances estimated for each nozzle type. These models were fitted using the SAS Version 9.4 procedure MIXED (SAS 1987).

\section{Speed trial}

A separate ANOVA was performed to test the effects of Speed (either 30 or 50 knots) for the Accu-Flo ${ }^{\mathrm{TM}} .028$ nozzle across all spray mixes.

\section{Droplet spectrum measurement}

All droplet spectra measurements were replicated three times in the wind tunnel at the Centre for Spray Technology
Application Research and Training, The University of Queensland, Gatton, Australia. The wind tunnel is a straightthrough blower design. The air speed was set as required for each application scenario. Nozzles were mounted individually on a vertical traverse. This was used to move the nozzle vertically up in the 1-m by $1-\mathrm{m}$ wind tunnel working section while sampling the spray using a laser positioned at an appropriate distance downwind for the spray type. For the Accu-Flo ${ }^{\mathrm{TM}}$ nozzles, this distance was approximately $2 \mathrm{~m}$ to allow for complete spray breakup, while sampling for the other nozzles was at a closer distance of $\sim 0.5 \mathrm{~m}$ because atomisation was complete closer to the nozzle. Each spray was applied at the required pressure, measured using a capillary connected to a pressure gauge and at the other end to the nozzle body/tip. All measurements were made using a Sympatec HELOS Vario laser diffraction instrument positioned entirely outside the wind tunnel, measuring light 
diffraction ranges to offer a dynamic size range of 0.5 to $3500 \mu \mathrm{m}$. Where possible, the entire spray plume was measured by traversing the nozzle vertically while sampling. Where this was not possible within the setup limitation, half the spray plume was measured for axi-symmetric sprays.

Tank mixing was done using 18-L metal containers, into which the carrier (tap water, free of particulates) was placed and the other products were added. Agitation was used to assure complete mixing and the sprays were displaced from the canisters using compressed air.

\section{AGDISP simulations}

Four AGDISP 8.29 simulations were undertaken to highlight the operational implications of choosing droplet spectra with differing characteristics. The base simulation (Appendix, Table A1) was kept constant to isolate droplet size spectrum effects. The four droplet size spectra (Tables 3 \& A2) represented a range of droplet sizes based on $D_{v 0.5}$ values ranging from 232 to $1200 \mu \mathrm{m}$ and driftable fractions from 0.00 to $20.42 \%$. The droplet spectra effects were characterised in terms of both predicted downwind spray drift and droplet density (i.e. number of droplets per unit leaf area) profiles through a representative pine canopy of $10 \mathrm{~m}$ height and mean one-sided leaf area index of 2.5. Droplet density was estimated based on the amount of spray deposited at each level in the canopy and the $\mathrm{D}_{\mathrm{v} 0.5}$ value. The application consisted of 20 flight lines, with the wind direction perpendicular to the flight lines, and the spray mix was characterised using the TDPA formulation.

\section{RESULTS}

\section{Main trial}

\section{Droplet-size spectra data}

Out of the 81 treatments (nozzle $\times$ operating conditions $\times$ spray mix) tested, only twelve produced spectra that were within one size class of the target class (Table 4), with
Table 3 Droplet spectra and air speed combinations used in the four AGDISP simulations.

\begin{tabular}{llllll}
\hline Nozzle type & $\begin{array}{l}\text { Nozzle } \\
\text { angle } \\
\left({ }^{\circ}\right)\end{array}$ & $\begin{array}{l}\text { Pres- } \\
\text { sure } \\
(\text { bar })\end{array}$ & $\begin{array}{l}\text { Air- } \\
\text { speed } \\
\text { (knots) }\end{array}$ & $\begin{array}{l}\mathrm{D}_{\mathrm{v} .05} \\
(\mu \mathrm{m})\end{array}$ & $\begin{array}{l}\text { Driftable } \\
\text { fraction } \\
(\%)\end{array}$ \\
\hline $\begin{array}{l}\mathrm{D} 6-45 \\
\mathrm{CP}-09-\end{array}$ & $0^{\circ}$ & 4 & 50 & 232 & 20.4 \\
$\begin{array}{l}0 \\
0.078-30^{\circ}\end{array}$ & 2 & 30 & 450 & 3.3 \\
$\begin{array}{l}\text { Accu-Flo } \\
.028\end{array}$ & $0^{\circ}$ & 2 & 50 & 609 & 1.8 \\
$\begin{array}{l}\text { Accu-Flo } \\
.028\end{array}$ & $0^{\circ}$ & 2 & 30 & 1200 & 0.0 \\
\hline
\end{tabular}

$\mathrm{D}_{\mathrm{v} 0.5}$ values ranging from 271 to $491 \mu \mathrm{m}$. However, only one nozzle, the CP-09, $0.078,30^{\circ}$, was in the target Coarse spectrum class specification $\left(D_{\mathrm{v} 0.5}\right.$ in the range of 326$400 \mu \mathrm{m})$. This nozzle met the target droplet size for all three spray mixes (Table 4 ) when used at $45^{\circ}$ with a pressure of 2 bars and airspeed of 30 knots. All other tests produced spectra that fell out of this range; one spectrum (D6-45, $0^{\circ}$, 4 bars, 50 knots, metsulfuron) was in the fine class $\left(D_{v 0.5}\right.$ of $219 \mu \mathrm{m}$ ) and all others were in the Extremely or Ultra Coarse classes with $D_{v 0.5}$ values ranging from 501 to $1360 \mu \mathrm{m}$.

The analysis of variance on droplet size data showed that most factors and their interactions had a statistically highly significant effect on all response variables, partly because variation between replicates was so low (Table 5). The factors having the largest effect on all response variables were nozzle type and angle and the interaction between these variables.

All three types of Accu-Flo ${ }^{\mathrm{TM}}$ and three of the four types of CP-09 nozzles tested produced the largest values of $D_{v 0.5}$ (Figure 1) when the nozzle angle was $0^{\circ}$. Changing the nozzle angle from $0^{\circ}$ to $45^{\circ}$ resulted in a large decrease in average $\mathrm{D}_{\mathrm{v} 0.5}$ from $934 \mu \mathrm{m}$ to $694 \mu \mathrm{m}$. However, the $\mathrm{D}_{\mathrm{v} 0.5}$ values from

Table 4 Nozzles, operating condition combinations and spray mixes that produced droplet size classes in the Medium $\left(\mathrm{D}_{\mathrm{v} 0.5}\right.$ 226-325 $\mu \mathrm{m})$, Coarse $\left(\mathrm{D}_{\mathrm{v} 0.5} 326-400 \mu \mathrm{m}\right)$ or Very Coarse $\left(\mathrm{D}_{\mathrm{v} 0.5} 401-500 \mu \mathrm{m}\right)$ ranges.

\begin{tabular}{|c|c|c|c|c|c|c|c|}
\hline Nozzle & $\begin{array}{c}\text { Nozzle angle } \\
\left({ }^{\circ}\right)\end{array}$ & $\begin{array}{l}\text { Pressure } \\
\text { (bar) }\end{array}$ & $\begin{array}{l}\text { Airspeed } \\
\text { (knots) }\end{array}$ & Spray mix & $\begin{array}{l}D_{v 0.5} \\
(\mu \mathrm{m})\end{array}$ & RS & $\begin{array}{c}\text { Driftable fraction } \\
(\%)\end{array}$ \\
\hline D6-45 & 0 & 4 & 50 & TDPA & 232 & 1.2 & 20.4 \\
\hline D6-45 & 0 & 4 & 50 & Water & 271 & 1.2 & 14.3 \\
\hline CP-09, 0.078, $30^{\circ}$ & 45 & 2 & 30 & TDPA & 329 & 0.9 & 5.1 \\
\hline CP-09, 0.078, $30^{\circ}$ & 45 & 2 & 30 & Metsulfuron & 357 & 0.9 & 3.2 \\
\hline CP-09, $0.078,30^{\circ}$ & 45 & 2 & 30 & Water & 385 & 1.1 & 3.2 \\
\hline Accu-Flo ${ }^{\mathrm{TM}} .028$ & 45 & 2 & 50 & TDPA & 419 & 1.3 & 6.6 \\
\hline Accu-Flo ${ }^{\mathrm{TM}} .028$ & 45 & 2 & 50 & Metsulfuron & 446 & 1.3 & 5.5 \\
\hline $\mathrm{CP}-09,0.078,30^{\circ}$ & 0 & 2 & 30 & TDPA & 449 & 1.2 & 3.3 \\
\hline CP-09, 0.125, 30 & 45 & 2 & 30 & Metsulfuron & 472 & 1.1 & 0.9 \\
\hline CP-09, $0.125,30^{\circ}$ & 45 & 2 & 30 & TDPA & 478 & 1.0 & 0.0 \\
\hline CP-09, 0.125, 30 & 45 & 2 & 30 & Water & 487 & 1.0 & 0.0 \\
\hline CP-09, 0.078, $5^{\circ}$ & 45 & 2 & 30 & Water & 491 & 0.8 & 0.0 \\
\hline
\end{tabular}


Table 5 Analysis of variance for the three response variables and main treatment factors: nozzle type, nozzle angle, and spray mixture.

\begin{tabular}{|c|c|c|c|c|c|}
\hline \multirow[t]{2}{*}{ Factors } & \multirow{2}{*}{$\begin{array}{l}\text { Num. } \\
\text { D.F. }^{\text {c }}\end{array}$} & \multirow{2}{*}{$\begin{array}{l}\text { Den. } \\
\text { D.F. }\end{array}$} & \multicolumn{3}{|c|}{ F-value } \\
\hline & & & $\mathrm{Dv}_{0.5}$ & $\begin{array}{l}\text { Relative } \\
\text { span }\end{array}$ & $\begin{array}{l}\text { Driftable } \\
\text { fraction }\end{array}$ \\
\hline Nozzle & 8 & 126 & $2333.4^{* *}$ & $338.9 * *$ & $512.8^{* *}$ \\
\hline Angle & 1 & 126 & $2711.3^{* *}$ & $37.1^{* *}$ & $110.8^{* *}$ \\
\hline Spray & 2 & 126 & $49.5^{* *}$ & $12.7^{* *}$ & $24.3^{* *}$ \\
\hline Nozzle $\times$ Angle & 8 & 126 & $405.7^{* *}$ & $21.4^{* *}$ & $153.4^{* *}$ \\
\hline Nozzle×Spray & 16 & 126 & $39.7^{* *}$ & $6.1^{* *}$ & $25.3^{* *}$ \\
\hline Spray $\times$ Angle & 2 & 126 & $26.4^{* *}$ & $4.2^{* *}$ & 2.1 \\
\hline $\begin{array}{l}\text { Nozzlex } \\
\text { Spray } \times \text { Angle }\end{array}$ & 16 & 126 & $6.3^{* *}$ & $4.4^{* *}$ & $10.4^{* *}$ \\
\hline
\end{tabular}

** $\mathrm{P}<0.001$

${ }^{\mathrm{a}}$ Numerator; ${ }^{\mathrm{b}}$ Denominator; ${ }^{\mathrm{c}}$ Degrees of freedom.

the CP nozzles were by far the most sensitive to nozzle angle (Figure 1).

Of all the nozzle types tested, the three types of Accu-Flo ${ }^{\mathrm{TM}}$ nozzle produced the smallest RS (Figure 2), with relatively low values between 0.4 and 0.6 , irrespective of nozzle angle. The other nozzle types produced a wider range of droplet sizes with RS values between about 0.9 and 1.5 irrespective of nozzle angle. The RS values for CP nozzles were most sensitive to nozzle angle and, as exceptions to the overall trend, changing the nozzle angle from $0^{\circ}$ to $45^{\circ}$ decreased $\mathrm{RS}$ with $30^{\circ} \mathrm{CP}$ nozzles.

Driftable fraction (volume of spray in droplets with diameters less than $150 \mu \mathrm{m}$ ) values were extremely low for all Accu-Flo ${ }^{\mathrm{TM}}$ nozzles tested irrespective of angle (Figure 3 ). Changing the nozzle angle from $0^{\circ}$ to $45^{\circ}$ increased the driftable fraction from an average (across all treatments) of $0.43 \%$ to $1.49 \%$, respectively. Nozzles producing the smallest $\mathrm{D}_{\mathrm{v} 0.5}$ values tended to have the largest driftable fractions (Figure 4). However, across all nozzles, angles and spray mixes, the driftable fractions were extremely low once the $\mathrm{D}_{\mathrm{v} 0.5}$ exceeded about $750 \mu \mathrm{m}$ with one exception, the CP-09, $0.125,30^{\circ}$ with the TDPA spray mix. The driftable fraction values tended to be lowest with CP-09 nozzles

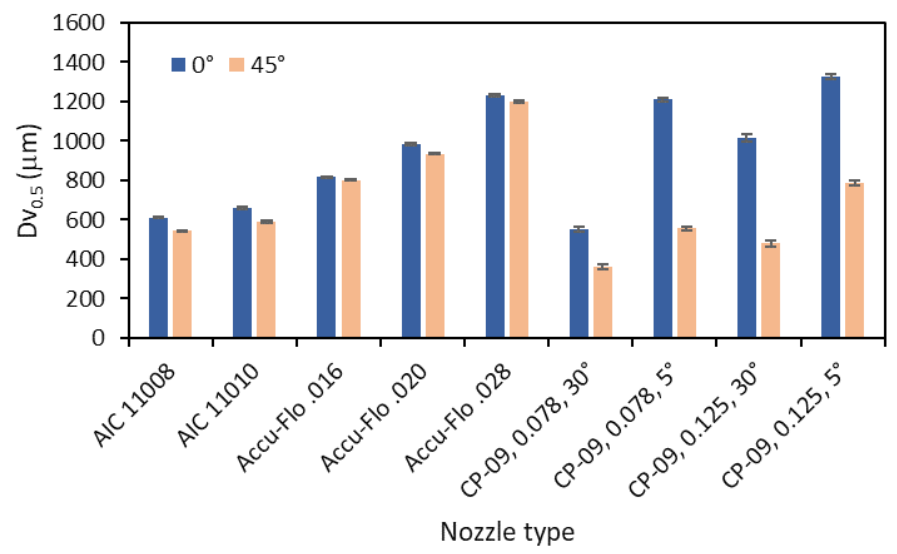

Figure 1 Effect of nozzle type and angle on volume median diameter $\left(\mathrm{D}_{\mathrm{v} 0.5}\right)$ values.

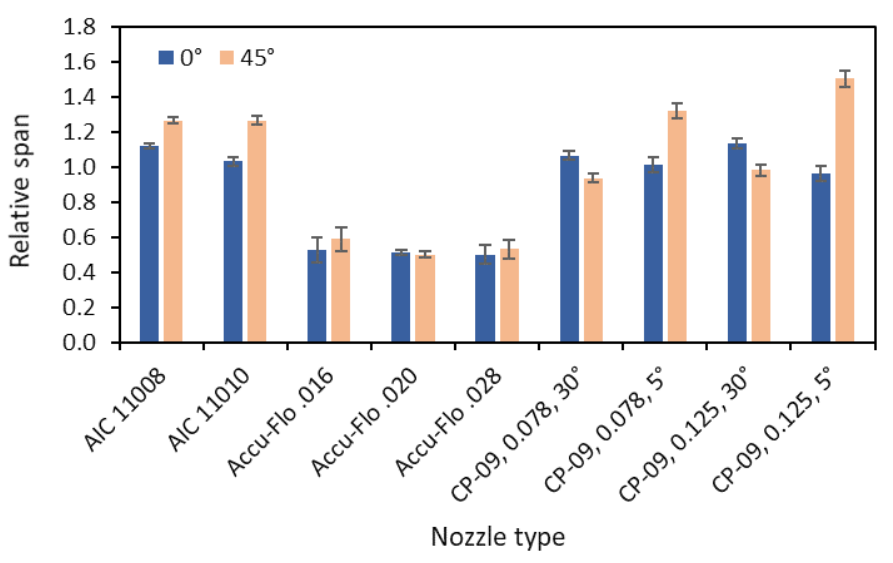

Figure 2 Effect of nozzle type and angle on RS.

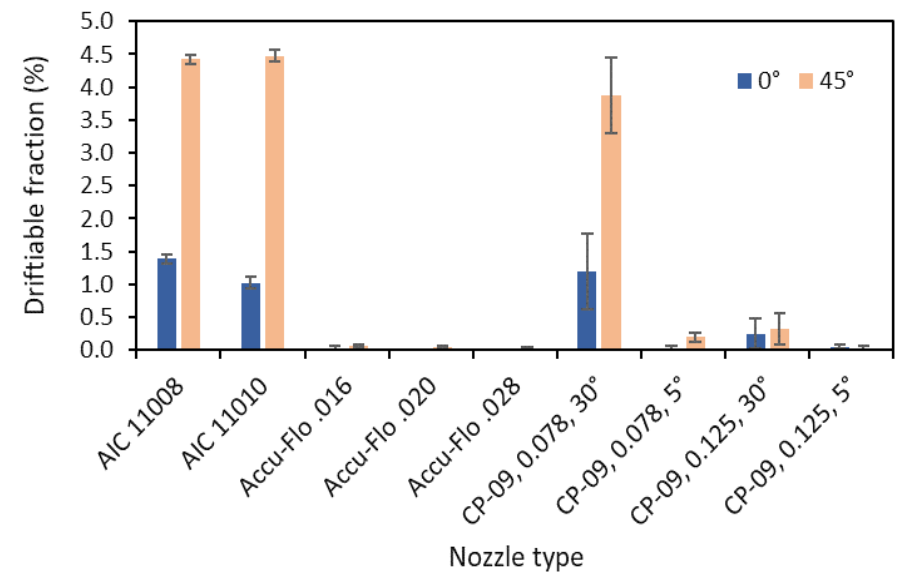

Figure 3 Effect of nozzle type and angle on driftable fraction (volume of spray in droplets with diameters $<150 \mu \mathrm{m}$ ).

for a given $D_{v 0.5}$ value below a threshold of about $700 \mu \mathrm{m}$ (Figure 4).

Overall, there was a small but significant effect of spray mix on the three dependent variables (Table 6). In general, water produced the largest $\mathrm{D}_{\mathrm{v} 0.5}$ and smallest driftable fraction and RS while TDPA produced the smallest $\mathrm{D}_{\mathrm{v} 0.5}$ and highest driftable fraction and RS. There were significant two-way and three-way interactions between nozzle, spray mix and nozzle angle but these effects were too small to be of practical relevance and with no obvious consistent trends (data not shown).

\section{Speed trial}

Increasing airspeed from 30 to 50 knots for the Accu-Flo ${ }^{\mathrm{TM}}$ .028 nozzle caused a large reduction in $\mathrm{D}_{\mathrm{v} 0.5}$ and increase in both driftable fraction and RS (Tables 7 and 8).

\section{AGDISP analysis}

Droplet density on foliage was predicted by AGDISP to increase substantially as droplet size decreased (Figure 5), even though total canopy deposition also decreased due to the higher quantum of spray drift beyond the spray block edge with the smaller droplet sizes (Table 9). Ground deposition increased as droplet size increased. At the extremes, the D6-45 $\left(\mathrm{D}_{\mathrm{v} 0.5}=232 \mu \mathrm{m}\right)$ nozzle at 50 knots airspeed deposits 


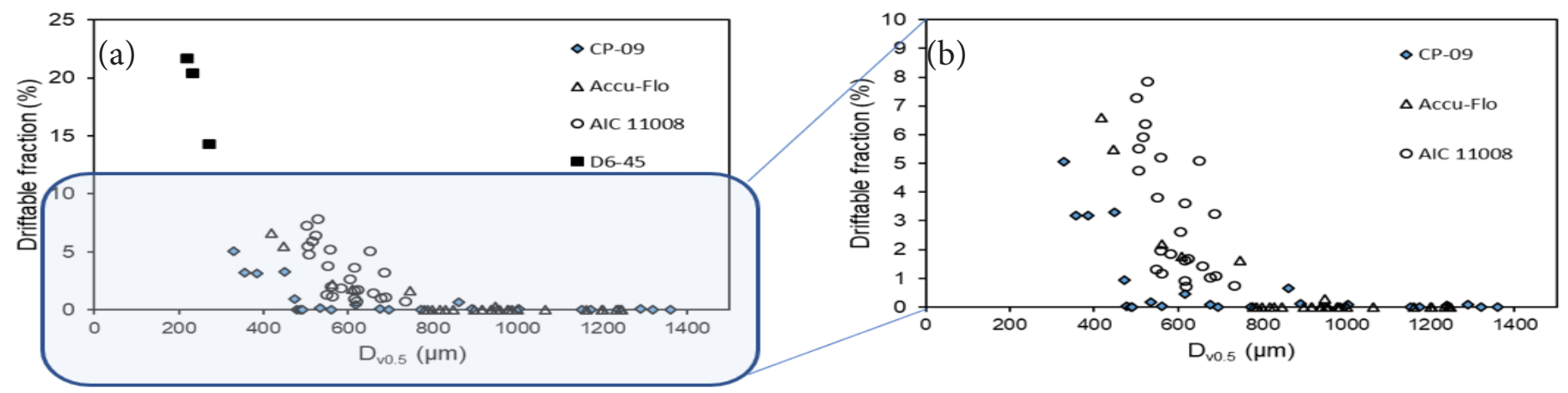

Figure 4 Relationship between volume median diameter $\left(D_{v 0.5}\right)$ and driftable fraction (volume of spray in droplets with diameters < $150 \mu \mathrm{m}$ ) across: (a) a number of nozzle types; and (b) with the D6-45 nozzle omitted for improved clarity of variation amongst other nozzles .

doses equivalent to $1 \%$ of the amount applied at about 195 $m$ downwind of the spray block compared to a distance of about $3.5 \mathrm{~m}$ for the Accu-Flo ${ }^{\mathrm{TM}} .028$ at 30 knots airspeed $\left(D_{v 0.5}=1200 \mu \mathrm{m}\right)$ (Figure 6). The CP-09-0.078-30 nozzle oriented at $0^{\circ}$ and at 30 knots airspeed had a smaller $\mathrm{D}_{\mathrm{v} 0.5}$ and higher driftable fraction than the Accu-Flo ${ }^{\mathrm{TM}} .028$ at 50 knots airspeed, however the effect of these spectra on downwind spray drift is complex. Up to about $66 \mathrm{~m}$ downwind of the spray block, drift is predicted to be higher with the CP-09-0.078-30 nozzle as might be expected from the droplet spectrum indices. However, beyond $66 \mathrm{~m}$, the two curves cross over, and drift levels are higher with the Accu-Flo ${ }^{\mathrm{TM}} .028,50$ knots droplet spectrum.

Table 6 Effect of spray mix on means and standard errors (in parentheses) of $\mathrm{D}_{\mathrm{v} 0.5}$, driftable fraction and RS.

\begin{tabular}{lccc}
\hline Spray mix & $\mathrm{D}_{\mathrm{v} 0.5}$ & $\mathrm{RS}$ & $\begin{array}{c}\text { Driftable fraction } \\
(\%)\end{array}$ \\
\hline Water & $843(4.0)$ & $0.87(0.016)$ & $0.62(0.086)$ \\
Metsulfuron & $812(4.0)$ & $0.93(0.016)$ & $0.82(0.086)$ \\
TDPA & $787(4.0)$ & $0.99(0.016)$ & $1.44(0.086)$ \\
\hline
\end{tabular}

Table 7 Analysis of variance for the Accu-Flo ${ }^{\mathrm{TM}} .028$ nozzle including the effects of air speed (30 or 50 knots) on the three response variables.

\begin{tabular}{|c|c|c|c|c|c|}
\hline \multirow[t]{2}{*}{ Effect } & \multirow{2}{*}{$\begin{array}{l}\text { Num. } \\
\text { D.F. }^{\mathrm{a}}\end{array}$} & \multirow{2}{*}{$\begin{array}{l}\text { Den. } \\
\text { D.F. }\end{array}$} & \multicolumn{3}{|c|}{ F-value } \\
\hline & & & $\mathrm{D}_{\mathrm{v} 0.5}$ & $\mathrm{RS}$ & $\begin{array}{l}\text { Driftable } \\
\text { fraction }\end{array}$ \\
\hline Angle & 1 & 24 & $400^{* *}$ & 1.3 & $127.8^{* *}$ \\
\hline Spray & 2 & 24 & $632^{* *}$ & $5.0^{*}$ & $50.4^{* *}$ \\
\hline Speed & 1 & 24 & $14060^{* *}$ & $223.3^{* *}$ & $433.0^{* *}$ \\
\hline Angle $\times$ Spray & 2 & 24 & $5^{*}$ & 1.0 & $11.6^{* *}$ \\
\hline Angle $\times$ Speed & 1 & 24 & $191^{* *}$ & 0.2 & $124.2^{* *}$ \\
\hline Spray $\times$ Speed & 2 & 24 & $409^{* *}$ & 0.8 & $52.5^{* *}$ \\
\hline
\end{tabular}

${ }^{*} \mathrm{P}<0.05,{ }^{* *} \mathrm{P}<0.001 ;{ }^{\text {a }}$ Numerator; ${ }^{\mathrm{b}}$ Denominator; ${ }^{\mathrm{c}}$ Degrees of freedom.

\section{DISCUSSION}

For any given aerial herbicide treatment, the choice of droplet size often represents a compromise between the benefit, usually increased efficacy, from improved foliar coverage achieved using smaller droplet sizes, versus the imperative to minimise risk from offsite herbicide drift, which is achieved using larger droplet sizes. Once a target droplet size for operational spraying has been selected, there are a limited number of sources for accessing information on how to achieve this size. Some manufacturers produce a wide range of similar nozzles types to choose from. Catalogues from manufacturers usually present a droplet size classification for the different types and sizes of nozzles available, but these classifications do not generally

Table 8 Effect of airspeed on means and standard errors (in parentheses) of the dependent variables $\mathrm{D}_{\mathrm{v} 0.5}, \mathrm{RS}$ and driftable fraction for the Accu-Flo ${ }^{\mathrm{TM}} .028$ nozzle.

\begin{tabular}{cccc}
\hline $\begin{array}{c}\text { Speed } \\
\text { (knots) }\end{array}$ & $\begin{array}{c}\mathrm{D}_{\mathrm{v} 0.5} \\
(\mu \mathrm{m})\end{array}$ & RS & $\begin{array}{c}\text { Driftable fraction } \\
(\%)\end{array}$ \\
\hline 30 & $1214(7)$ & $0.515(0.066)$ & $0.0(0.2)$ \\
50 & $622(7)$ & $1.192(0.066)$ & $3.0(0.2)$ \\
\hline
\end{tabular}

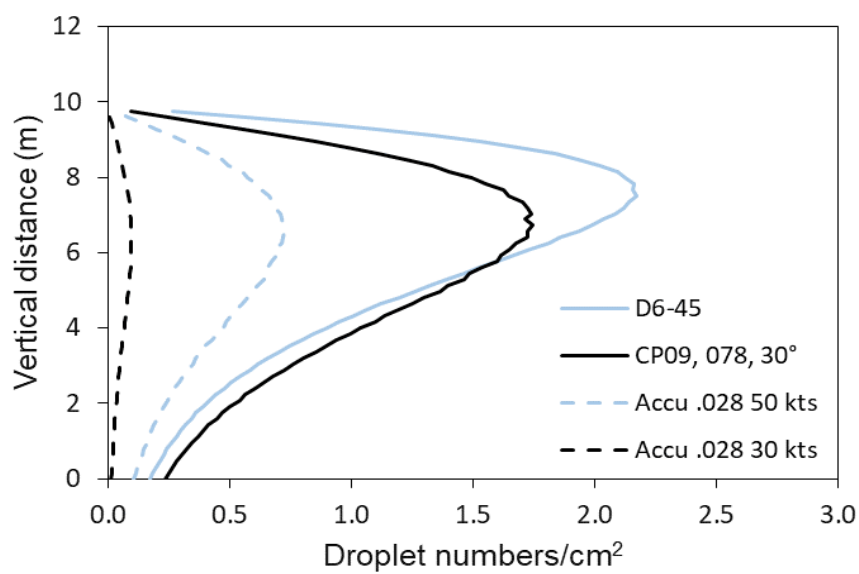

Figure 5 Estimated droplet density profiles through the pine canopy (AGDISP model). 
Table 9 Predicted fate of spray material from the four droplet size spectra (AGDISP model) (Nozzle angle $=0^{\circ}$ in all cases).

\begin{tabular}{|c|c|c|c|c|c|c|}
\hline \multirow[t]{2}{*}{ Nozzle type } & \multirow[t]{2}{*}{$\begin{array}{l}\text { Airspeed } \\
\text { (knots) }\end{array}$} & \multirow[t]{2}{*}{$\begin{array}{l}D_{v 05} \\
(\mu \mathrm{m})\end{array}$} & \multirow[t]{2}{*}{$\begin{array}{c}\text { Driftable fraction } \\
(\%)\end{array}$} & \multicolumn{3}{|c|}{$\begin{array}{c}\text { Fate of spray material } \\
(\%)\end{array}$} \\
\hline & & & & Canopy & Airborne & Ground \\
\hline D6-45 & 50 & 232 & 20.4 & 76.0 & 19.5 & 4.5 \\
\hline CP-09-0.078-30 & 30 & 450 & 3.3 & 87.0 & 5.0 & 8.0 \\
\hline Accu-Flo ${ }^{\mathrm{TM}} .028$ & 50 & 609 & 1.8 & 88.0 & 3.0 & 9.0 \\
\hline Accu-Flo ${ }^{\mathrm{TM}} .028$ & 30 & 1200 & 0.0 & 89.5 & 0.5 & 10.0 \\
\hline
\end{tabular}

account for the effects on droplet size of formulation, nozzle orientation and air shear, all significant factors for aerial application (Sundaram et al. 1985; Bouse 1994; Hoffmann et al. 2008; Fritz et al. 2009). This paucity of data for aerial applicators was highlighted in the current study by the fact that out of the 27 nozzle $x 3$ operating condition (nozzle angle, air speed and pressure) combinations tested for each of two operational spray mixes (and a water control) used in control of invasive wilding conifers in New Zealand, only one nozzle (CP-09-0.078-30 oriented at $45^{\circ}$ and at $30 \mathrm{kts}$ airspeed) met the target droplet size specification (volume median diameter or $D_{v 0.5}$ of $350 \mu \mathrm{m}$ ). However, the droplet size database created provided useful generalisations for aerial pesticide applicators or invasive weed managers.

For the flying speeds around 30 knots and where drift minimisation is the primary concern, driftable fraction values for all three of the Accu-Flo ${ }^{\mathrm{TM}}$ nozzles tested were generally $0 \%$, or close to $0 \%$, irrespective of nozzle angle or spray mix. Along with the Accu-Flo ${ }^{\mathrm{TM}}$ nozzles, the CP-09
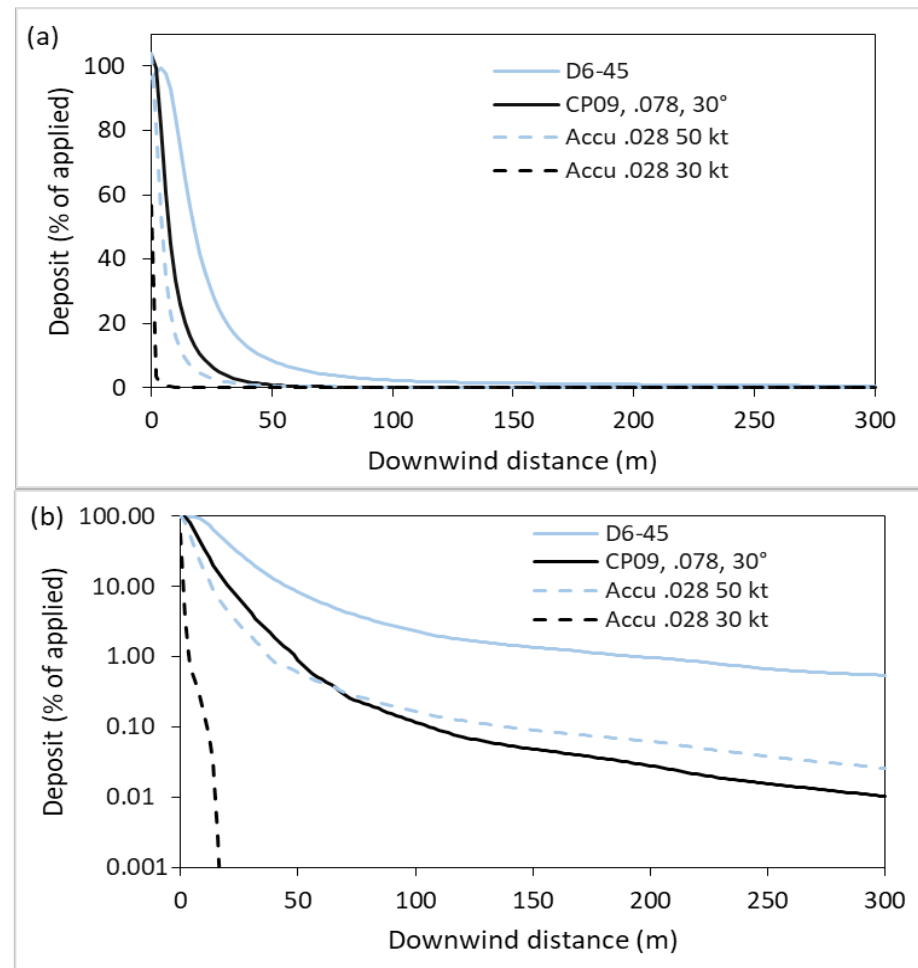

Figure 6 Predicted spray drift beyond the downwind edge of the spray block $(0 \mathrm{~m})$ plotted on: (a) a linear; and (b) a logarithmic scale (AGDISP model). nozzles produced the largest $\mathrm{D}_{\mathrm{v} 0.5}$ values and in many cases produced comparably low driftable fractions. However, the $\mathrm{CP}$ nozzles were much more sensitive to changes in nozzle angle than Accu-Flo ${ }^{\mathrm{TM}}$ nozzles indicating that care is needed in setting them up for a target droplet size and that small changes in helicopter angle of flight could have a relatively large effect on $\mathrm{D}_{\mathrm{v} 0.5}$ and driftable fraction with these nozzles. Nevertheless, for nozzle and operating condition combinations producing $\mathrm{D}_{\mathrm{v} 0.5}$ values below a threshold of about $700 \mu \mathrm{m}, \mathrm{CP}-09$ nozzles would be the best choice to minimise the driftable fraction.

While spray mix did not have a large effect on the droplet spectrum parameters evaluated, the TDPA mix tended to increase the potential for spray drift more so than the water or metsulfuron mixes. Both the TDPA and metsulfuron spray mixes had different formulated active ingredients and adjuvants that would have altered the physical properties of the spray mixes in different ways compared with water alone. While these changes undoubtedly caused the observed variation in droplet spectrum parameters, the physical properties of each mix were not specifically studied.

Predictions of spray drift from the AGDISP model (Figure 6) also highlight that the use of simple droplet spectrum indices, such as driftable fraction, can be misleading when making inferences about the potential for spray drift or foliar coverage and demonstrate the benefits of using a mechanistic simulation model to compare the performance of different operational scenarios rather than judging results based on simple rules of thumb. For example, the CP-09$0.078-30^{\circ}$ nozzle has a higher driftable fraction value than the Accu-Flo ${ }^{\mathrm{TM}} .028,50$ knots droplet spectrum; yet, beyond $66 \mathrm{~m}$ downwind, drift levels are higher with the latter. This result is explained by the larger volume of spray in droplets with diameters $<86 \mu \mathrm{m}$ with the Accu-Flo ${ }^{\mathrm{TM}} .028,50$ knots droplet spectrum.

These results also indicate that operational spraying is often being undertaken with droplet size classes substantially larger, often by a factor of two or three, than operational guidelines currently recommend. Spray coverage within the conifer canopies will be significantly reduced by using these much larger than expected droplet size classes. However, given that the operational specifications are generally achieving efficacy targets, apart from the risk of striping (poor control) when the flight lines don't achieve sufficient overlap, this result suggests there could be potential to reduce total spray volumes (and potentially herbicide active ingredient rates) if smaller droplet sizes were utilised in line with operational recommendations. 


\section{CONCLUSIONS}

This study has highlighted that most operational spraying for wilding conifer control has been undertaken using much larger droplet sizes than expected, with $D_{v 0.5}$ values often two to three times higher than that recommended. A database has been generated to improve nozzle selection to match specific droplet size criteria. Of the 10 types of nozzle tested, only the CP- $09,0.078,30^{\circ}$ when used at $45^{\circ}$ met the coarse spectrum specification $\left(D_{v 0.5}\right.$ in the range of $\left.326-400 \mu \mathrm{m}\right)$ for all three spray mixes. However, under these conditions, this nozzle produced a large driftable fraction. None of the three Accu-Flo ${ }^{\mathrm{TM}}$ nozzles tested met the target droplet size specification but produced very few fine droplets making them good choices for reducing spray drift potential.

\section{ACKNOWLEDGEMENTS}

Funding for this work was provided by the NZ MBIE Endeavour Fund Contract C09X1611, "Winning Against Wildings" and NZ Forest Growers Research.

\section{REFERENCES}

ASABE-Standards 2009. S572.1. Spray Nozzle Classification by Droplet Spectra. St. Joseph, MI: ASABE.

Bilanin AJ, Teske ME, Barry JW, Ekblad RB 1989. AGDISP: The aircraft spray dispersion model, code development and experimental validation. Transactions of the ASAE 32: 327-0334. https://doi.org/10.13031/2013.31005

Bird SL, Perry SG, Ray SL, Teske ME 2002. Evaluation of the AgDISP aerial spray algorithms in the AgDRIFT model. Environmental Toxicology and Chemistry 21: 672-681. https://doi.org/10.1002/etc.5620210328

Bouse L 1994. Effect of nozzle type and operation on spray droplet size. Transactions of the ASAE-American Society of Agricultural Engineers 37: 1389-1400. https://doi. org/10.13031/2013.28219

Briden K, Raal P, Gous S Improving methods for wilding conifer control in New ZealandPp. 369-371.

Fox RD, Derksen RC, Brazee RD, Ozkan H Air-blast/airassisted application equipment and driftCiteseer. Pp. 108-129.

Fritz B, Hoffmann W, Bagley W 2009. Effects of spray mixtures on droplet size under aerial application conditions and implications on drift. Applied Engineering in Agriculture 26: 21-29. https://doi.org/10.13031/2013.29467

Fritz BK, Hoffmann WC, Czaczyk Z, Bagley W, Kruger G, Henry R 2012. Measurement and classification methods using the ASAE S572. 1 reference nozzles. Journal of Plant Protection Research 52: 447-457. https://doi. org/10.2478/v10045-012-0072-x

Froude VA 2011. Wilding conifers in New Zealand: beyond the status report. [Report prepared for the Ministry of Agriculture \& Forestry]. Bay of Islands, NZ: Pacific EcoLogic. https://www.wildingconifers.org.nz/assets/ Uploads/Wilding-Conifers-in-NZ-Beyond-the-statusreport.pdf

Gous S, Watt M, Richardson B, Kimberley M 2010. Herbicide screening trial to control dormant wilding Pinus contorta, P. mugo and Pseudotsuga menziesii during winter. New
Zealand Journal of Forestry Science 40: 153-159.

Gous S, Raal P, Watt MS 2014. Dense wilding conifer control with aerially applied herbicides in New Zealand. 44: 4. https://doi.org/10.1186/1179-5395-44-4

Gous S, Raal P, Kimberley M, Watt M 2015. Chemical control of isolated invasive conifers using a novel aerial spot application method. Weed Research 55: 380-386. https://doi.org/10.1111/wre.12147

Hewitt AJ, Johnson DR, Fish JD, Hermansky CG, Valcore DL 2002. Development of the spray drift task force database for aerial applications. Environmental Toxicology and Chemistry 21: 648-658. https://doi.org/10.1002/ etc. 5620210326

Hoffmann WC, Hewitt A, Ross J, Bagley W, Martin D, Fritz B 2008. Spray adjuvant effects on droplet size spectra measured by three laser-based systems in a high-speed wind tunnel. Journal of ASTM International 5: 1-12. https://doi.org/10.1520/JAI101233

Ledgard $\mathrm{N}$ 2001. The spread of lodgepole pine (Pinus contorta, Dougl.) in New Zealand. Forest Ecology and Management 141: 43-57. https://doi.org/10.1016/ S0378-1127(00)00488-6

NWCMS 2014. The right tree in the right place: New Zealand Wilding Conifer Management Strategy 20152030. Wellington, New Zealand: Ministry for Primary Industries. $\quad$ https://www.wildingconifers.org.nz/ assets/Uploads/2014-new-zealand-wilding-conifermanagement-strategy-3.pdf

Ray JW, Davenhill NA 1991. Evaluation of herbicides for the control of Pinus contorta. Proceedings of the FortyFourth New Zealand Weed and Pest Control Conference. Rotorua, New Zealand Plant Protection Society. https:// doi.org/10.30843/nzpp.1991.44.10795

Richardson B, Thistle H 2006. Measured and predicted aerial spray interception by a young Pinus radiata canopy. Transactions of the ASABE 49: 15-23. https:// doi.org/10.13031/2013.20230

SAS 1987. SAS/STATTM guide for personal computers. Cary NSI, Inc.

Simberloff D, Nunez MA, Ledgard NJ, Pauchard A, Richardson DM, Sarasola M, Van Wilgen BW, Zalba SM, Zenni RD, Bustamante R 2010. Spread and impact of introduced conifers in South America: lessons from other southern hemisphere regions. Austral Ecology 35: 489-504. https://doi.org/10.1111/j.1442-9993.2009.02058.x

Sundaram A, Sundaram K, Cadogan B 1985. Influence of formulation properties on droplet spectra and soil residues of aminocarb aerial sprays in conifer forests. Journal of Environmental Science Health Part B 20: 167186. https://doi.org/10.1080/03601238509372474

Teske M, Thistle H, Ice G2003. Technical advances in modeling aerially applied sprays. Transactions of the ASAE 46: 985-993. https://doi.org/10.13031/2013.13955

Teske M, Thistle H, Londergan R 2011. Modification of droplet evaporation in the simulation of fine droplet motion using AGDISP. Transactions of the ASABE 54: 417-421. https://doi.org/10.13031/2013.36444 
APPENDIX

Table A1 Summary of common AGDISP inputs over the four simulations.

\begin{tabular}{|c|c|}
\hline Input variable & Value $^{\mathrm{a}}$ \\
\hline \multicolumn{2}{|l|}{ Aircraft } \\
\hline Aircraft type & Eurocopter AS 350 B3 (Squirrel) \\
\hline Release height (m) & 18 \\
\hline Flying speed (knots) & 30 or 50 knots (see Table A2) \\
\hline Flight lines & 20 \\
\hline \multicolumn{2}{|l|}{ Application technique } \\
\hline Nozzles & Distributed evenly to $80 \%$ rotor diameter \\
\hline Droplet spectra & See Table A2. \\
\hline \multicolumn{2}{|l|}{ Spray Material } \\
\hline Material & TDPA spray mix \\
\hline Active ingredient (\%) & 13.5 \\
\hline Additive (\%) & 7.25 \\
\hline Non-volatile fraction & 0.2075 \\
\hline Volume rate $\mathrm{L} \mathrm{ha}^{-1}$ & 400 \\
\hline \multicolumn{2}{|l|}{ Swath } \\
\hline Swath width (m) & 10 \\
\hline \multicolumn{2}{|c|}{ Meteorology (reference height 2 m) } \\
\hline Wind speed $\left(\mathrm{m} \mathrm{s}^{-1}\right)$ & 2 \\
\hline Wind direction $\left({ }^{\circ}\right)$ & -90 \\
\hline Temperature $\left({ }^{\circ} \mathrm{C}\right)$ & 20 \\
\hline Relative humidity (\%) & 65 \\
\hline \multicolumn{2}{|l|}{ Atmospheric Stability } \\
\hline Stability & Overcast \\
\hline \multicolumn{2}{|l|}{ Canopy } \\
\hline Type & LAI - Generic Conifer \\
\hline Height (m) & 10 \\
\hline Leaf area index (LAI) & 2.5 \\
\hline Element size $(\mathrm{cm})$ & 1 \\
\hline Element type & Cylinder \\
\hline
\end{tabular}


Table A2 Droplet size spectra used in AGDISP simulations.

\begin{tabular}{|c|c|c|c|c|}
\hline & \multicolumn{3}{|c|}{ Nozzle } & \multirow[b]{2}{*}{ D6-45 } \\
\hline & $\mathrm{CP}-09,0.078,30^{\circ}$ & Accu-Flo ${ }^{\mathrm{TM}} 0.28$ & Accu-Flo ${ }^{\mathrm{TM}} 0.28$ & \\
\hline Nozzle angle $\left({ }^{\circ}\right)$ & 0 & 0 & 0 & 0 \\
\hline Pressure (bar) & 2 & 2 & 2 & 4 \\
\hline Airspeed (kts) & 30 & 50 & 30 & 50 \\
\hline Drop size class upper limit $(\mu \mathrm{m})$ & \multicolumn{4}{|c|}{ Cumulative spray volume (\%) } \\
\hline 18 & 0.00 & 0.00 & 0.0000 & 0.13 \\
\hline 22 & 0.00 & 0.00 & 0.0000 & 0.20 \\
\hline 26 & 0.00 & 0.00 & 0.0000 & 0.30 \\
\hline 30 & 0.00 & 0.00 & 0.0000 & 0.40 \\
\hline 36 & 0.00 & 0.00 & 0.0000 & 0.61 \\
\hline 44 & 0.00 & 0.00 & 0.0000 & 0.95 \\
\hline 52 & 0.00 & 0.00 & 0.0000 & 1.41 \\
\hline 62 & 0.02 & 0.07 & 0.0000 & 2.19 \\
\hline 74 & 0.08 & 0.18 & 0.0000 & 3.45 \\
\hline 86 & 0.21 & 0.32 & 0.0000 & 5.09 \\
\hline 100 & 0.50 & 0.53 & 0.0000 & 7.52 \\
\hline 120 & 1.27 & 0.92 & 0.0000 & 11.91 \\
\hline 150 & 3.31 & 1.76 & 0.0000 & 20.42 \\
\hline 180 & 6.18 & 2.92 & 0.0000 & 30.69 \\
\hline 210 & 9.65 & 4.38 & 0.0000 & 41.80 \\
\hline 250 & 15.02 & 6.77 & 0.0000 & 56.60 \\
\hline 300 & 22.78 & 10.49 & 0.0900 & 72.99 \\
\hline 360 & 33.27 & 16.12 & 0.2267 & 86.78 \\
\hline 420 & 44.48 & 23.13 & 0.3833 & 94.22 \\
\hline 500 & 59.53 & 34.10 & 0.5700 & 98.18 \\
\hline 600 & 76.17 & 48.72 & 0.7767 & 99.66 \\
\hline 720 & 89.62 & 65.14 & 1.2433 & 100.00 \\
\hline 860 & 96.81 & 79.86 & 3.8800 & 100.00 \\
\hline 1020 & 99.28 & 90.28 & 17.3133 & 100.00 \\
\hline 1220 & 99.66 & 96.57 & 53.7700 & 100.00 \\
\hline 1460 & 99.85 & 99.40 & 91.8333 & 100.00 \\
\hline 1740 & 99.99 & 100.00 & 100.0000 & 100.00 \\
\hline 2060 & 100.00 & 100.00 & 100.0000 & 100.00 \\
\hline
\end{tabular}

